\title{
Investigation of pile penetration in calcareous soft rock using X-ray computed tomography
}

\author{
Fernando Alvarez-Borges MSc, PhD \\ Diamond Light Source, Didcot, UK (Orcid:0000-0002-6940-9918) \\ (corresponding author: \\ fernando.alvarez-borges@diamond.ac.uk) \\ Sharif Ahmed PhD \\ Diamond Light Source, Didcot, UK (Orcid:0000-0002-3290-3592)
}

\author{
Bangalore Narasimha Madhusudhan MEng, PhD \\ Faculty of Engineering and Physical Sciences, University of Southampton, \\ Southampton, UK (Orcid:0000-0002-2570-5934) \\ David Richards MSt, PhD, CEng, FICE \\ Faculty of Engineering and Physical Sciences, University of Southampton, \\ Southampton, UK (Orcid:0000-0002-3819-7297)
}

Penetration of open- and closed-ended model piles into intact chalk, a soft calcareous rock, was investigated using microfocus X-ray computed tomography (XCT). Three-dimensional images of the specimens showed that the piles crushed and densified the chalk in their path, creating a crushed chalk annulus around the shaft, a region of compressed destructured chalk below the tip, and fractures across cemented regions of the specimen. Laserdiffraction particle-size analyses of the crushed chalk annulus after exhumation showed limited difference with laboratory-remoulded chalk, which suggested thorough de-cementation. Installation stresses and XCT-derived densities were paired using a simplified cylindrical cavity expansion solution to estimate effective radial stress-void ratio states at the pile tip during penetration. More complex numerical solutions could not be applied using the available data. This approach posed significant problems, as it could not suitably incorporate hardening and nonlinear stiffness behaviours of chalk during pile penetration, nor account for the creation of discontinuities. However, effective radial stress-void ratio estimates were found to converge with the reconstituted critical state line of the material at high stresses and low void ratios. This partially supported the use of a critical state framework to characterise pile penetration in chalk, as proposed in recent literature.

\section{Notation}

$a$

$b$

C

$D_{\mathrm{i}} \quad$ internal pile diameter

$D_{\text {o }} \quad$ external (outside) pile diameter

$E_{\mathrm{c}} \quad$ Young's modulus of the Chalk mass (formation)

$E_{\mathrm{p}} \quad$ Young's modulus of the specimen confinement of scaled models

$E_{r=a} \quad$ radial stiffness of the specimen confinement of scaled models

$E_{r=R} \quad$ radial stiffness at the plastic-elastic boundary of the Chalk mass around a field-scale pile cavity expansion parameter from Salgado et al. (1997) effective unit weight bulk unit weight unit weight of water radial strain on the internal wall of the specimen confinement of scaled models radial strain at the plastic-elastic boundary of the Chalk mass around a field-scale pile circumferential strain on the external wall of the specimen confinement of scaled models Poisson's ratio of the Chalk mass (formation) Poisson's ratio of the specimen confinement of scaled models major principal stress cavity expansion limit pressure and radial effective stress acting on the pile shaft

$\sigma_{r=a}^{\prime} \quad$ radial effective stress on the internal wall of the specimen confinement of scaled models

$\sigma_{r=R}^{\prime} \quad$ radial effective stress at the plastic-elastic boundary of the Chalk mass around a field-scale pile

$\sigma_{\mathrm{vi}}^{\prime} \quad$ in situ vertical effective stress

$\sigma_{\mathrm{z}}^{\prime} \quad$ effective vertical soil resistance to penetration under the pile tip

$\tau_{\text {sf }} \quad$ ultimate unit shaft friction on piles

$\phi^{\prime} \quad$ angle of friction of soil

$\phi_{\mathrm{c}}^{\prime} \quad$ critical state angle of friction of soil 
International Journal of Physical Modelling in Geotechnics Volume 22 Issue 1
Investigation of pile penetration in

calcareous soft rock using X-ray

computed tomography

Alvarez-Borges, Ahmed, Madhusudhan and

Richards $\phi_{\mathrm{p}}^{\prime} \quad$ peak angle of friction of soil

$\psi \quad$ angle of dilation of soil

\section{Introduction}

Weak rocks are intermediate geomaterials between soil and rock that exhibit relatively low interparticle bond strengths. They are common worldwide but represent important challenges for civil engineering works. These arise in part from the rupture of their cementitious bonds under moderate stresses and the transfer of these stresses to the porous granular fabric, which may deform substantially (Clayton and Serratrice, 1997; Leroueil and Vaughan, 1990). To anticipate and quantify these behaviours, a number of theoretical frameworks attempt to characterise the mechanical performance of weak rocks using soil mechanics concepts with parameters that account for the role of structure (e.g. Cuccovillo and Coop, 1999; Lagioia and Nova, 1995). However, difficulties in the determination of 'operational' values for these parameters and the application of these theoretical models arise from $(a)$ alterations in the natural structure during sampling, $(b)$ the need for highly specialised geotechnical testing techniques and $(c)$ the high variability of soft rocks (Kanji, 2014; Zhai et al., 2017). Thus, engineering designs commonly rely, at least during preliminary stages, on empirical or semi-empirical approaches. A typical example is the design of the driven piles used to support offshore infrastructure in areas of the North Sea underlain by chalk, a soft calcareous rock formed by fossilised microscopic skeletal remains of coccolithophores (Clayton et al., 2003). Pile installation crushes the material and forms a destructured chalk interface or 'annulus' around the pile (Hobbs and Atkinson, 1993; Lord et al., 2002). The shear strength of this interface, interpreted as ultimate unit shaft friction $\left(\tau_{\mathrm{sf}}\right)$, controls the uplift resistance of the pile. As $\tau_{\mathrm{sf}}$ is difficult to estimate, current guidelines advise an average $\tau_{\mathrm{sf}}$ design value of $20 \mathrm{kPa}$ for most in situ conditions, based on a small number of onshore pile compression and/or pull-out tests (Lord et al., 2002). The accuracy of this design value has been the subject of considerable debate (Jardine et al., 2018), and research on the vertical loading capacity of driven piles in chalk is ongoing. However, the mechanisms involved in the creation of the crushed soft rock annulus and its in situ characteristics have not been thoroughly studied.

To provide insight on this matter, an investigation has been carried out involving the application of X-ray computed tomography (XCT) before and after the slow monotonic insertion of cylindrical elements representing miniature piles into intact chalk cores. The 'model piles', the installation rate and the intact condition of the chalk specimens did not aim to accurately reproduce field-scale conditions. Instead, the objective was to observe and quantify changes in chalk density associated with penetration-induced loss of interparticle bonding, as well as the potential link between said changes in density with penetration resistance. The testing methodology and outcomes of these studies are presented in this paper.

\section{Methodology}

\subsection{Sample characteristics and specimen preparation}

Intact chalk samples were obtained from a quarry near St Nicholas-at-Wade, Kent, United Kingdom. The Margate Chalk Member overlies the Seaford Formation in this area (Aldiss et al., 2004; Bristow et al., 1997), and block samples of about $30 \mathrm{~cm}$ in each dimension were cut from the latter. Seaford Chalk is soft and white and often exhibits a grid of thin, denser veins a few millimetres in thickness (Mortimore, 1986). Its calcium carbonate $\left(\mathrm{CaCO}_{3}\right)$ content generally exceeds 98\% (Hancock, 1975). Further information on the characteristics of the chalk at this sampling site are available in the theses by Buckley (2018) and Alvarez-Borges (2019).

The samples were submerged in de-aired water for a minimum of 10 days. Cylindrical specimens of $100 \mathrm{~mm}$ diameter were then sculpted using a soil lathe. Specimen geometry is presented in Table 1. Specimens were then placed on an aluminium test pedestal and confined by a $5 \mathrm{~mm}$-thick polymethyl methacrylate (Perspex $\left.{ }^{\circledR}\right)$ tube bolted to the pedestal at its lower end. Gaps between the specimen and confinement ( $\approx 5 \mathrm{~mm}$ wide) were filled using a high-strength low-viscosity epoxy resin (Robnor PX672H). A 5-10 mm head of de-aired water was maintained at all times (including resin curing time, pile installation stages and XCT scanning sessions) to maintain a high saturation ratio.

\subsection{Test rig}

The pile jacking/XCT scanning hardware was custom designed to carry out the installation of the model pile using an Instron universal machine and to attach the specimen to the XCT scanner rotating stage for imaging. The device consists of the elements shown in Figure 1, labelled A-H. The characteristics and functions of each element are presented in Table 2, and photographs of the assembled rig are shown in Figure 2. Elements A-G were employed during model pile installation. Parts D, F and G were removed prior to XCT imaging, while element A was substituted with the spacer element $\mathrm{H}$. All parts used during XCT imaging $(\mathrm{B}, \mathrm{C}, \mathrm{E}$ and $\mathrm{H}$ ) were made from non-ferrous materials to minimise image artefacts.

\subsection{Model pile installation}

Solid flat-tipped (test XCT01) and tubular open-ended (test XCT02) thermoplastic model piles were used. Plastic materials were employed due to their relatively high strength and low X-ray attenuation properties. The solid pile measured $6.284 \mathrm{~mm}$ in the outside diameter $\left(D_{\mathrm{o}}\right)$, while the tubular pile 
Table 1. XCT specimen and experiment details

$\begin{array}{lll} & \text { XCT01 } & \text { XCT02 } \\ \text { Mean height: } \mathrm{mm} & 119.77 & 135.96 \\ \text { Mean diameter: } \mathrm{mm} & 99.23 & 99.92 \\ \text { Mean bulk density: } \mathrm{Mg} / \mathrm{m}^{3} & 1.974 & 1.973 \\ \text { Mean dry density: } \mathrm{Mg} / \mathrm{m}^{3} & 1.545 & 1.546 \\ \text { Pile material } & \text { Polyether ether ketone (PEEK) } & \text { Polymethyl methacrylate (Perspex®) } \\ \text { Pile } D_{0}: \mathrm{mm} & 6.284 \pm 0.010 & 7.940 \pm 0.010 \\ \text { Pile } D_{\mathrm{i}}: \mathrm{mm} & - & 5.94 \pm 0.010 \\ \text { Tip condition } & \text { Flat, closed-ended } & \text { Flat, open-ended } \\ \text { Embedded pile length at step 1: } \mathrm{mm}^{\mathrm{a}} & 18.166 & 15.503 \\ \text { Embedded pile length at step 2: } \mathrm{mm}^{\mathrm{a}} & 36.175 & 34.295 \\ \text { Embedded pile length at step 3: } \mathrm{mm}^{\mathrm{a}} & - & 38.680\end{array}$

${ }^{a}$ XCT-derived

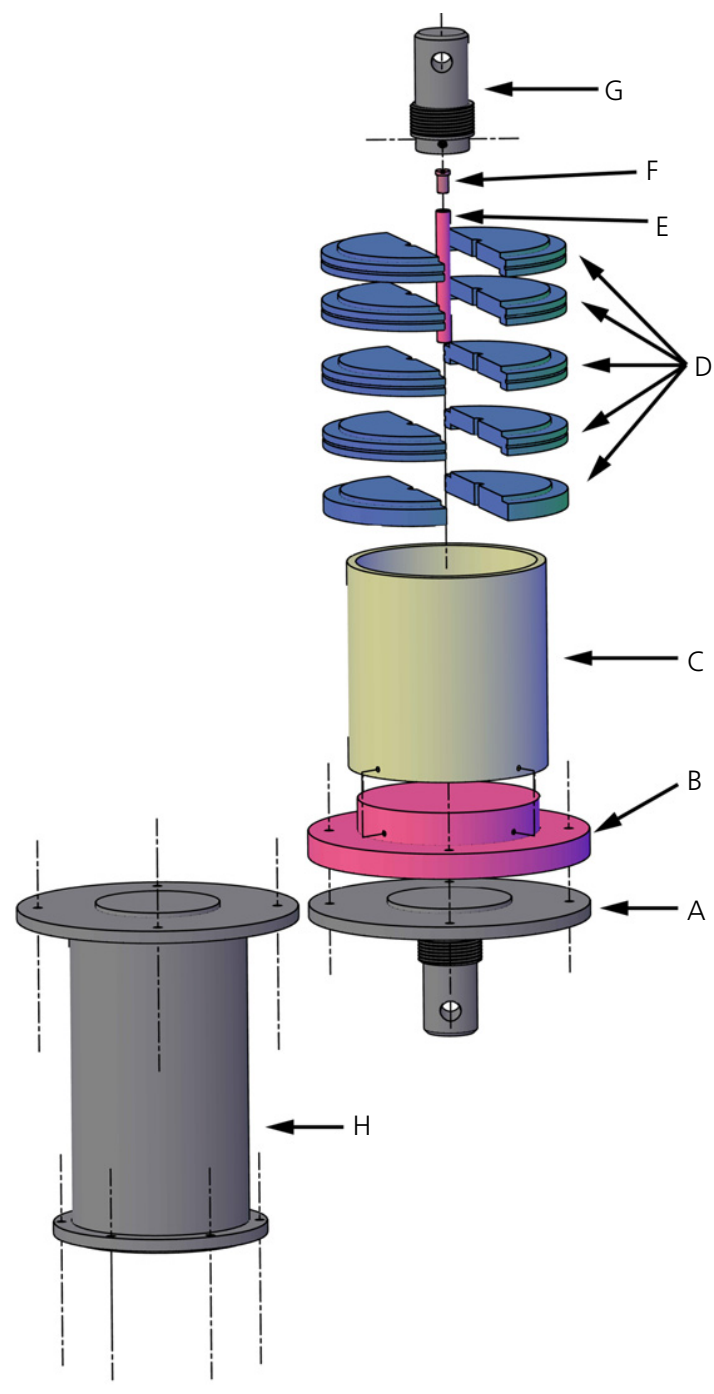

Figure 1. Assembly diagram of model pile jacking/scanning rig measured $7.940 \mathrm{~mm}$ in $D_{\mathrm{o}}$ and $5.94 \mathrm{~mm}$ in the inside diameter $\left(D_{\mathrm{i}}\right)$. Thus, the cross-section area of the pile used in XCT02 was about $60 \%$ of that of XCT01. A medium grit sandpaper was applied to the outside surface of the piles to increase the relative roughness of the interface (ratio of maximum centreline roughness to median grain diameter; Kishida and Uesugi, 1987) and promote failure within the chalk (Chan et al., 2019). Further details on the pile elements are given in Table 1.

Pile installation was carried out outside the XCT scanning bay using an electromechanical Instron universal testing machine (3400 Table Model Series). The model pile head was gripped by a custom fixture (part G) by way of grub screws (Table 2; Figure 1; Figure 2). The head of the tubular pile was fitted with a cylindrical metal insert to prevent crushing of the element while fastening these screws (part F). The aluminium pedestal on which the specimen rested was bolted to the compression -tension plate (part A). A split case confinement device was fitted around the model piles above the specimen surface to guide the pile and reduce deflection during installation.

Pile penetration was displacement controlled at $0.174 \mathrm{~mm} / \mathrm{min}$ (measured at the pile head), which is approximately 1000 times slower than the $1200 \mathrm{~mm} / \mathrm{min}$ standard penetration velocity of a $36 \mathrm{~mm}$ diameter cone penetrometer test (CPT) probe after discounting the difference in size. Such a low rate was intended to allow for fully drained penetration. In comparison, the fullsize piles $\left(D_{\mathrm{o}}=508 \mathrm{~mm}\right)$ impact-driven by Buckley et al. (2020) at the St Nicholas-at-Wade site were installed at rates of about $1500 \mathrm{~mm} / \mathrm{min}$.

Two installation stages were performed in XCT01, while three steps were used in XCT02. The target pile head displacement for each stage was $20 \mathrm{~mm}$, though the third installation stage in XCT02 was halted prematurely due to pile head damage. 
International Journal of Physical Modelling in Geotechnics Volume 22 Issue 1
Investigation of pile penetration in calcareous soft rock using X-ray

computed tomography

Alvarez-Borges, Ahmed, Madhusudhan and

Richards

Table 2. Jacking/scanning rig elements and functions

\begin{tabular}{|c|c|c|}
\hline Part & Material & Description \\
\hline A - Instron compression-tension plate & EN1A Steel & $\begin{array}{l}\text { Fixture attaching part B to the Instron test frame. Features a central seating ridge } \\
\text { and four through holes to secure with part B and allow for tension loading. }\end{array}$ \\
\hline B - Testing pedestal & 2024 Aluminium & $\begin{array}{l}\text { Base plate for chalk specimen. Attached to } A \text { by four screws. Features a centred } \\
\text { circular recess on bottom surface to improve coupling with parts } A \text { and } H \text {. }\end{array}$ \\
\hline C - Specimen confinement & Perspex® & $\begin{array}{l}125 \mathrm{~mm} \text { diameter } \times 5 \mathrm{~mm} \text { thick and } 120 \mathrm{~mm} \text { high pipe casing for the chalk } \\
\text { specimen. Attached to B by four screws. }\end{array}$ \\
\hline D - Split-case pile confinement & 6063 Aluminium & $\begin{array}{l}\text { Guides pile during installation. Formed by diametrically cut discs with a } \\
\text { circumferential groove and a circular recess on the bottom surface. Assembled } \\
\text { using cable ties and fitted into part C (Figure 2(a)). }\end{array}$ \\
\hline E - Model pile & Perspex $® / P E E K$ & Cylindrical solid bar or tubular element (see Table 1). \\
\hline F - Pile head insert & EN1A Steel & $\begin{array}{l}\text { Inserted at the head of tubular pile to prevent damage by the grub-screw grip of } \\
\text { element } \mathrm{G} \text {. Features a longitudinal through-hole and a groove on the top } \\
\text { surface as air-release. }\end{array}$ \\
\hline G - Pile head grip Instron fixture & EN1A Steel & $\begin{array}{l}\text { Element attaching the pile head to the Instron crosshead by way of four grub } \\
\text { screws. }\end{array}$ \\
\hline H - Scanning pedestal & 6063 Aluminium & $\begin{array}{l}\text { Replaces element A during XCT scanning. Features a central seating ridge. } \\
\text { Attaches the rig by way of part B to the XCT scanner rotating stage while } \\
\text { providing an offset distance from it to prevent image artefacts. }\end{array}$ \\
\hline
\end{tabular}
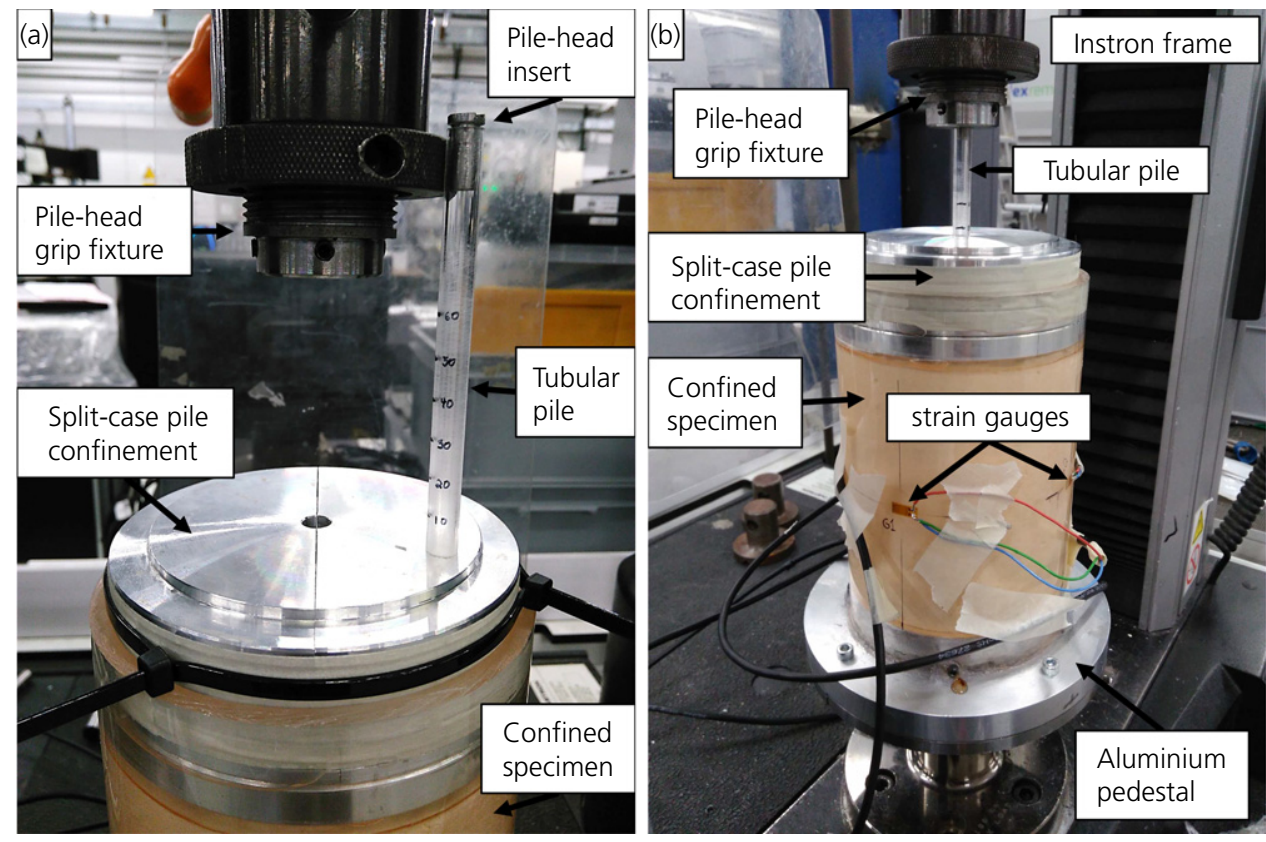

Figure 2. Assembled model pile jacking/scanning rig

The Perspex ${ }^{\circledR}$ confinement pipe was externally instrumented with linear strain gauges placed at two mid-specimen height locations on diametrically opposite positions to measure circumferential strain (Figure 2(b)). Strain gauges were connected to a Micro-Measurements System 8000 StrainSmart data acquisition and signal conditioning unit.

\subsection{Application of micro-focus XCT}

XCT scanning is carried out by producing two-dimensional (2D) radiographs of a specimen from different directions. In the device used in this investigation (Nikon 450/225 kV Hutch system at the University of Southampton's $\mu$-Vis X-ray Imaging Centre), the cone-beam X-ray source and flat-panel 
International Journal of Physical Modelling in Geotechnics Volume 22 Issue 1
Investigation of pile penetration in calcareous soft rock using X-ray computed tomography

Alvarez-Borges, Ahmed, Madhusudhan and Richards detector remain static while the specimen rotates on an electromechanical stage. A three-dimensional (3D) image is produced by reconstructing the $2 \mathrm{D}$ projections around the axis of rotation of the specimen (Cnudde and Boone, 2013; Ketcham and Carlson, 2001). X-ray attenuation is approximately linearly correlated with bulk density in materials of homogeneous mean effective atomic number (Mull, 1984; Phillips and Lannutti, 1997). Therefore, local variations in bulk density are recorded as the different greyscale intensities in each voxel of the reconstructed volumes (Desrues, 2004; Otani et al., 2010).

$\mathrm{XCT}$ data were acquired at $405 \mathrm{kV}$-power using an average current of approximately 230 and $240 \mu \mathrm{A}$ for XCT01 and XCT02, respectively. The scan resolution was $104 \mu \mathrm{m}$, approximately. An aluminium bowtie filter was used to mitigate beam hardening and $X Y$-plane beam path-induced image artefacts (Zhang et al., 2013). The former results from the lower energy $\mathrm{X}$-rays in the polychromatic beam being preferentially attenuated or extinguished at small depths within the specimen (Hsieh, 2015). The latter arises from the shorter beam-path lengths at the edges of the specimen, which result in much larger fluence being delivered to the detector (Mail et al., 2009).

Specimens were scanned before the installation of the model pile and after each penetration stage, and scan sessions were labelled using numbers after the specimen name. The field of view excluded the Perspex ${ }^{\circledR}$ casing tube and resin.

\subsection{Model pile exhumation and post-test measurements}

At the end of the experiments, the Perspex ${ }^{\circledR}$ casing and resin fill were carefully cut using a hacksaw. Specimen XCT01 exhibited longitudinal ( $Z$-axis) fracturing during pile installation, thus, the specimen was split along these discontinuities. For XCT02, which did not exhibit lengthwise fracturing, a shallow $(\approx 10 \mathrm{~mm}$ ) groove was longitudinally cut into the specimen using the hacksaw, and a metal wedge was carefully pushed into the groove, thus inducing tensile failure and longitudinal splitting.

Small amounts $(<1 \mathrm{~g})$ of annulus material were sampled from XCT01 at every $10 \mathrm{~mm}$ of embedment depth using a scalpel, with sampling locations labelled A-E as shown in Figure 3. Particle-size analyses (PSAs) were carried out on these samples using a laser-diffraction method (employing a Mastersizer 3000 device and following guidance in BS ISO 1330:2009 (BSI, 2009)). The split specimen was then left to air-dry for a minimum of 4 weeks. Thereafter, small $(<2 \mathrm{~mm}$ in maximum dimension) samples were carved out of the annulus feature of XCT01 employing a scalpel and adhered to microscopy stubs using carbon cement. The samples were then sputter-coated in gold using magnetron deposition and examined using scanning electron microscopy (SEM), thus obtaining micrographs of the material in contact with the pile shaft.

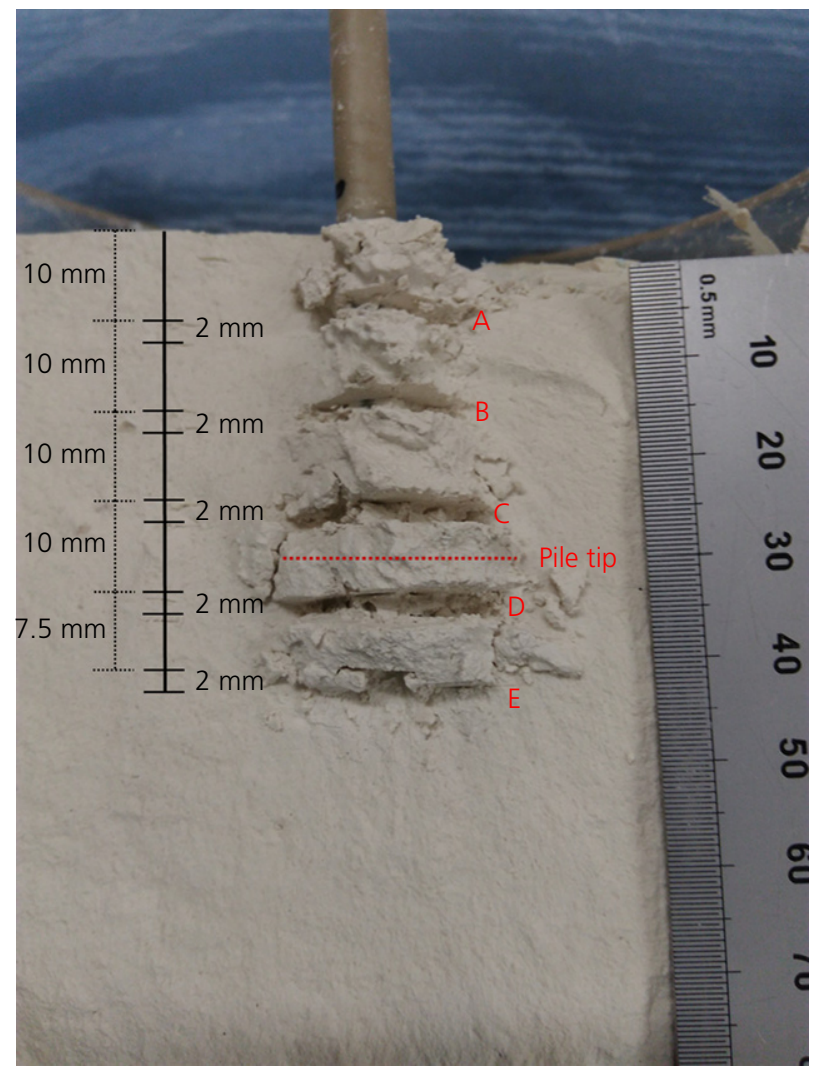

Figure 3. Particle-size analysis sampling detail for XCT01

The very small volume of crushed chalk forming the annulus of XCT02 resulted insufficient to recover SEM samples or to retrieve enough material to reach the optimal obscuration range of the PSA equipment, and therefore, micrographs and particle-size distributions (PSDs) could not be obtained.

Post-test intact bulk densities of the specimen periphery or 'far-field' region were measured by applying the 'gas jar' method described by Clayton (1983) to specimen trims (Figure 4), for both XCT01 and XCT02.

\subsection{Identification of the pile-chalk interface}

While the remoulded chalk annulus could be recognised in the reconstructed XCT images by visual inspection, an unambiguous procedure was required to identify the voxels in contact with the pile shaft. A script was written and compiled in Matlab to do this. The working principles of the code were as follows.

- To reduce computing time, a region of interest (ROI) along the vertical $(Z)$ axis was defined. This ROI contained the central portion of the $3 \mathrm{D}$ image in which the pile and annulus were located (Figure 5(a)). 
International Journal of Physical Modelling in Geotechnics Volume 22 Issue 1
Investigation of pile penetration in calcareous soft rock using X-ray computed tomography

Alvarez-Borges, Ahmed, Madhusudhan and Richards (a)

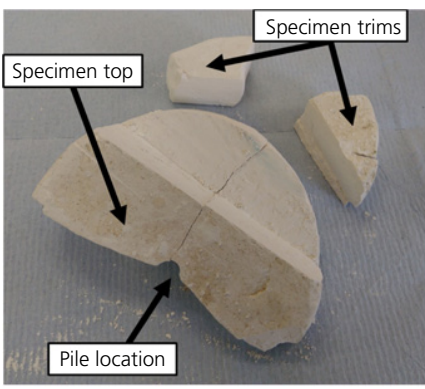

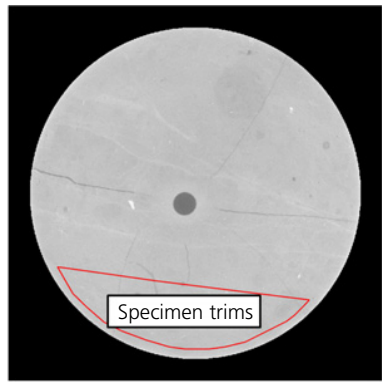

(b)
Figure 4. (a) Extraction of trims from XCT01 for post-test density measurements; (b) location of density sampling zone on horizontal slice of volume XCT01-02

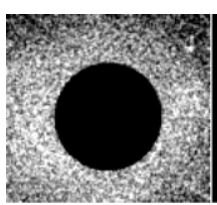

(a)

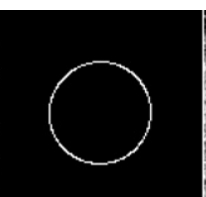

(b)

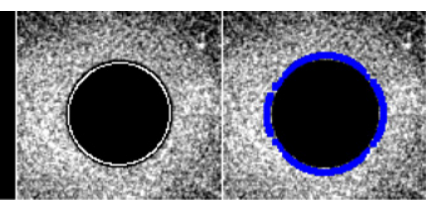

(c)

(d)
Figure 5. (a) $X Y$ view of ROI of XCT01-02 (the pile is the dark circle); (b) Canny edge detector output; (c) detected edge in (a); (d) pile-adjacent annulus pixels shown in blue

- A Canny edge detector algorithm (Canny, 1986) was applied to each slice of the ROI. The algorithm returned a binary image depicting the pile cross-section perimeter, approximately (Figures 5(b) and 5(c)).

- The edge voxel coordinates obtained from the Canny detector did not correspond to the precise pile-chalk boundary due to 'partial volume averaging', where subvoxel size detail is lost by the averaging of the different $\mathrm{X}$-ray attenuations occurring within the voxel volume (Ketcham and Carlson, 2001). To be able to collect grey value $(\mathrm{GV})$ information from the actual crushed chalk annulus in close vicinity of the pile, edge coordinates in each slice were expanded by three voxels in the radial direction, and the edge thickness was increased by one voxel (Figures 5(c) and 5(d)).

\section{Results}

Figure 6(a) shows pile head loads applied during installation against measured pile head displacements. In stage 2 and thereafter, test data exhibit a clear 'yield' prior to a linear increase in load with pile head displacement, though this yield occurred at much smaller loads in XCT02 than in XCT01. Additionally, a notably serrated pile head load against displacement profile is observed for XCT02. Circumferential strains measured

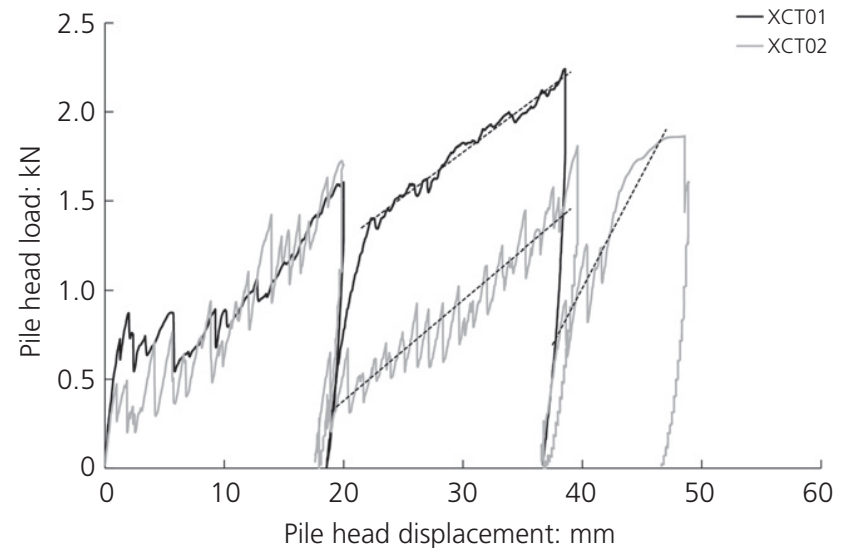

(a)

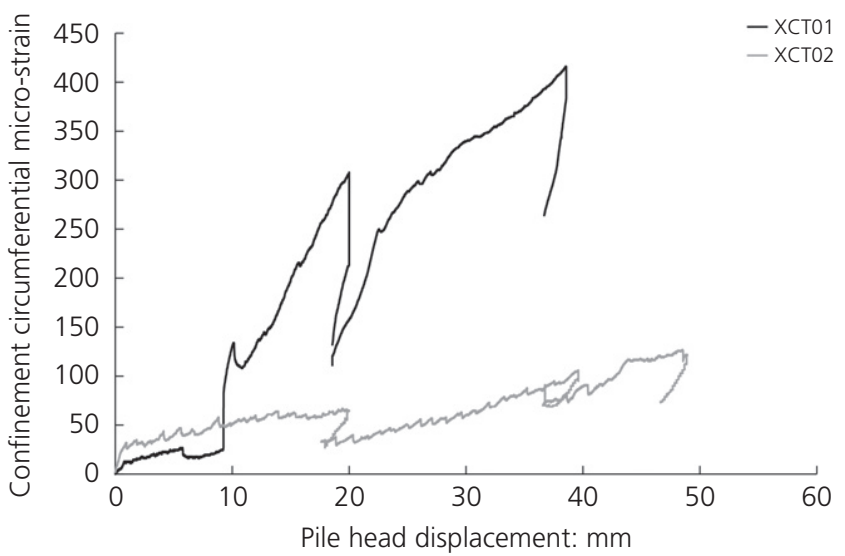

(b)

Figure 6. (a) Pile head load during penetration; (b) circumferential strain on specimen confinement during pile penetration

during pile penetration are shown in Figure 6(b). The abrupt increase in strain at about $10 \mathrm{~cm}$ pile head displacement in XCT01 was approximately concurrent with the appearance of visible fractures in the specimen.

Figure 7 depicts 3D vertical cross-section views of the reconstructed and processed XCT volumes before installation (a, c) and after the final installation step $(b, d)$ of both experiments. The volumes do not show the upper portion and top surface of the specimens, due to a cropping procedure performed to remove cone-beam effect artefacts (Markins, 2014). The pile used in XCT01 was noted to have lost verticality during installation.

Top-bottom profiles of the average GV of the annulus region in close contact with the pile shaft in each horizontal (XY) slice of the post-installation digital volumes are shown in Figure 8(a). For each slice, data have been normalised by the far-field average $\mathrm{GV}$ of the region from which physical density 
International Journal of Physical Modelling in Geotechnics Volume 22 Issue 1
Investigation of pile penetration in calcareous soft rock using X-ray computed tomography

Alvarez-Borges, Ahmed, Madhusudhan and Richards

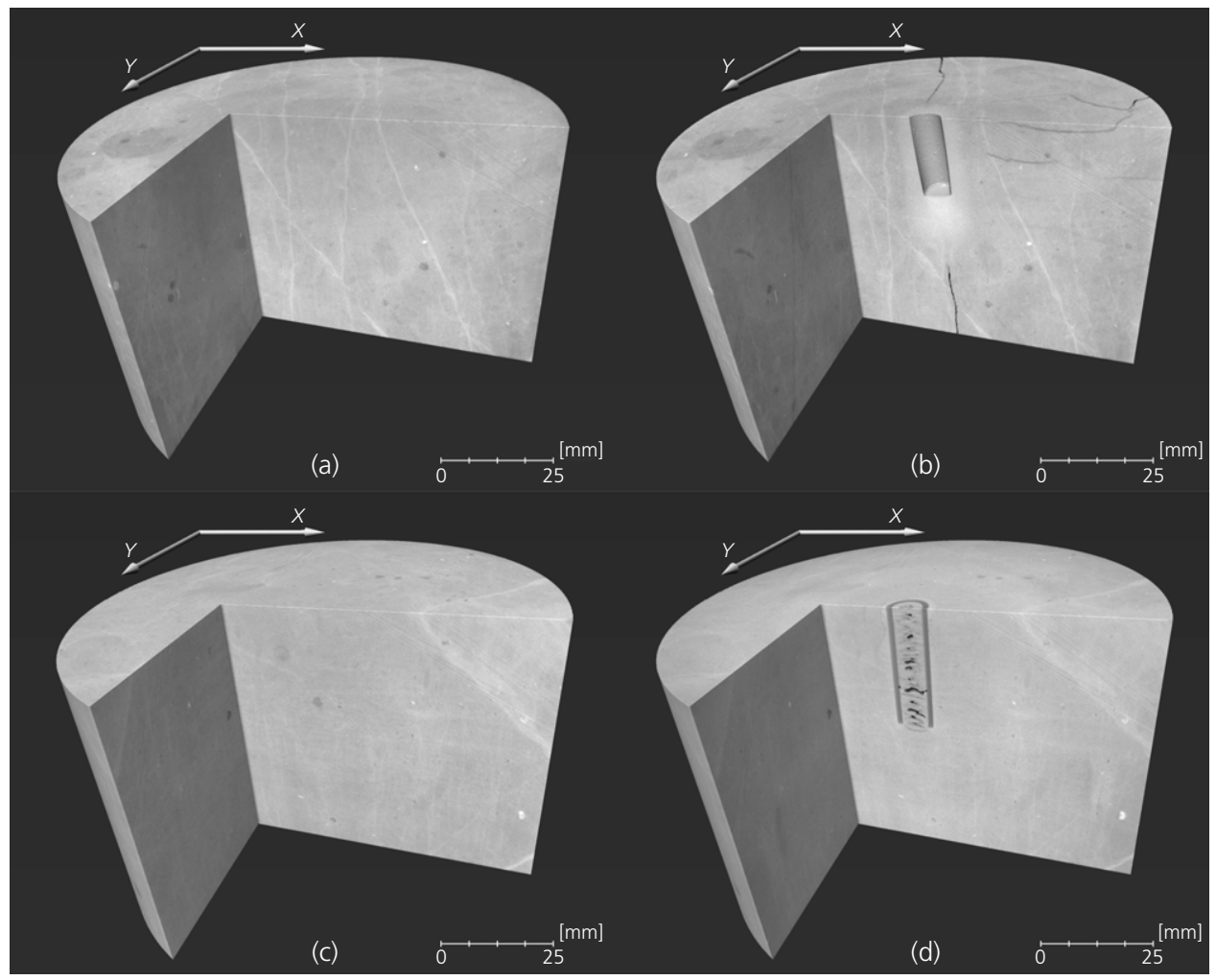

Figure 7. 3D views of clipping box cut through reconstructed volumes (a) XCT01-00; (b) XCT01-02; (c) XCT02-00 and (d) XCT02-03. Generated using Avizo Lite Software

measurements were obtained (Figure 4). These profiles are compared with GV data collected using the annulus coordinates in the pre-installation volumes, likewise averaged for each slice and normalised by the far-field average GV. These profiles denote an increase in greyscale intensity of up to $10 \%$ with respect to pre-installation conditions. Considering that X-ray attenuation in monomineralic geomaterials is approximately linearly correlated with bulk density, the annulus to far-field greyscale ratios were preliminarily assumed to be equivalent to the density ratios between these two regions. Thus, these ratios were multiplied by the physically measured bulk density of the far-field region at each depth (employing a depth-based regression line fitting the discrete density measurements) and used to determine average annulus void ratio (e) profiles, assuming fully saturated conditions and using (Madhusudhan and Baudet, 2014):

1. $e=\frac{G_{\mathrm{s}} \gamma_{\mathrm{w}}-\gamma_{\mathrm{b}}}{\gamma_{\mathrm{b}}-\gamma_{\mathrm{w}}}$

where $G_{\mathrm{s}}$ is the specific gravity of calcite, assumed to be 2.7 (Clayton, 1983), and $\gamma_{\mathrm{w}}$ and $\gamma_{\mathrm{b}}$ are the bulk unit weight of water and chalk, respectively. The results are presented in
Figure $8(\mathrm{~b})$. This procedure was similarly applied to a central ROI $(250 \times 250 \times 500$ voxels $)$ of XCT01-02 and XCT02-03 to produce porosity ( $n$ ) maps (Figure 9 ) by using:

2. $n=\frac{e}{1+e}$

Post-exhumation PSA and SEM results are shown in Figures 10(a) and 11. The former does not reveal important differences in PSD with sampling location. The latter exhibits very densely arranged grains, limited evidence of intact coccoliths and an instance of coccolith damage by edge-chipping and/or abrasion. A micrograph of intact chalk has been included in Figure 11(e) for reference.

\section{Discussion}

\subsection{Limitations of XCT-based pile-chalk interface density measurements}

XCT-based annulus density quantification suggests low void ratios (Figure 8(b)). In general, these void ratio estimates are qualitatively supported by SEM images of the pile-annulus 
International Journal of Physical Modelling in Geotechnics Volume 22 Issue 1
Investigation of pile penetration in calcareous soft rock using X-ray computed tomography

Alvarez-Borges, Ahmed, Madhusudhan and Richards

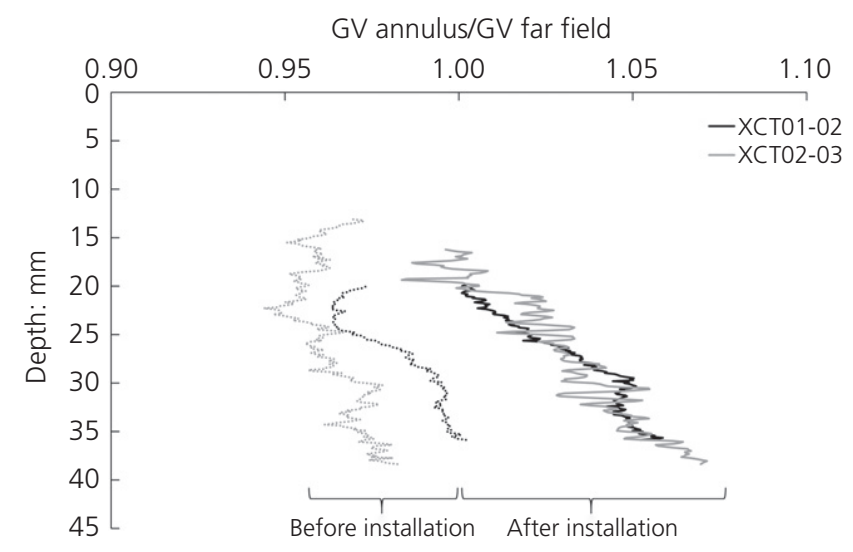

(a)

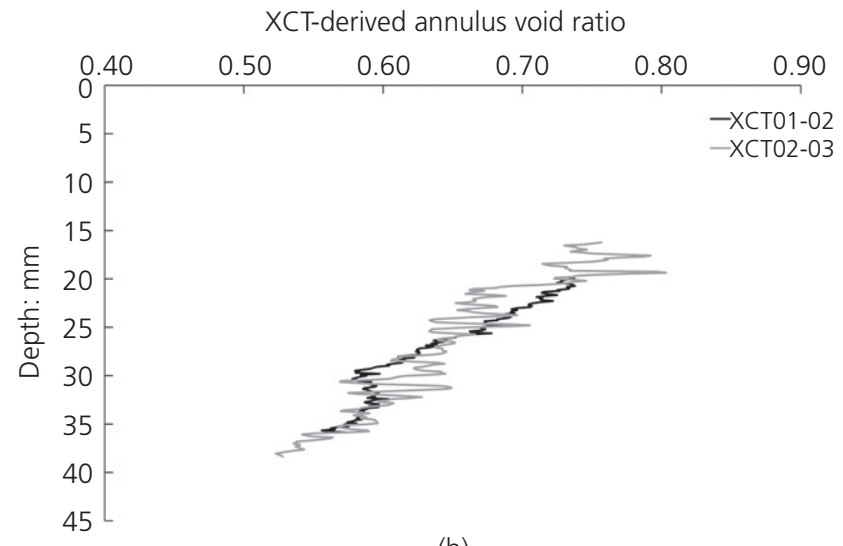

(b)

Figure 8. (a) Depth-based profile of GVs in annulus coordinates normalised by the average GV of the far-field region of Figure 4; (b) XCT-derived depth-based average annulus void ratio profiles

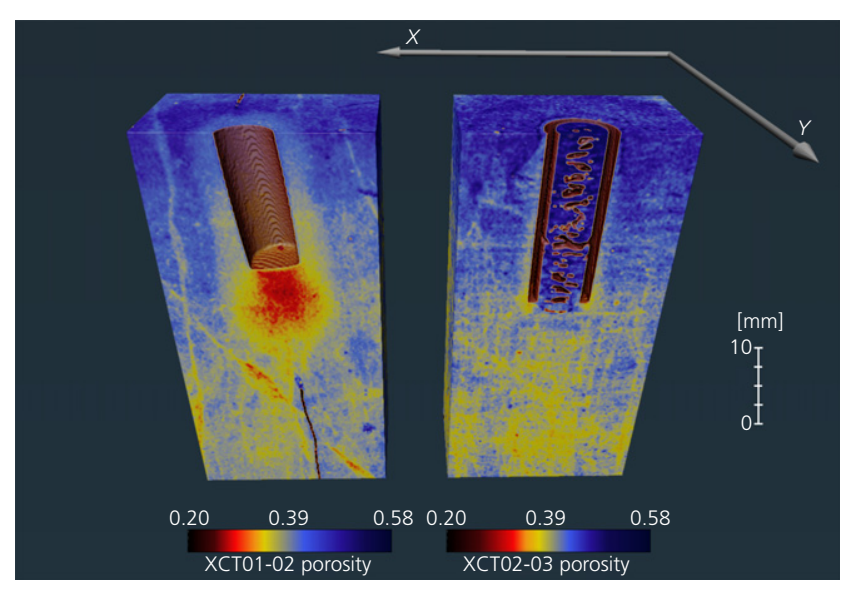

Figure 9. 3D view of porosity distribution across central portion of XCT02-02 and XCT03-03. Generated using Avizo Lite Software

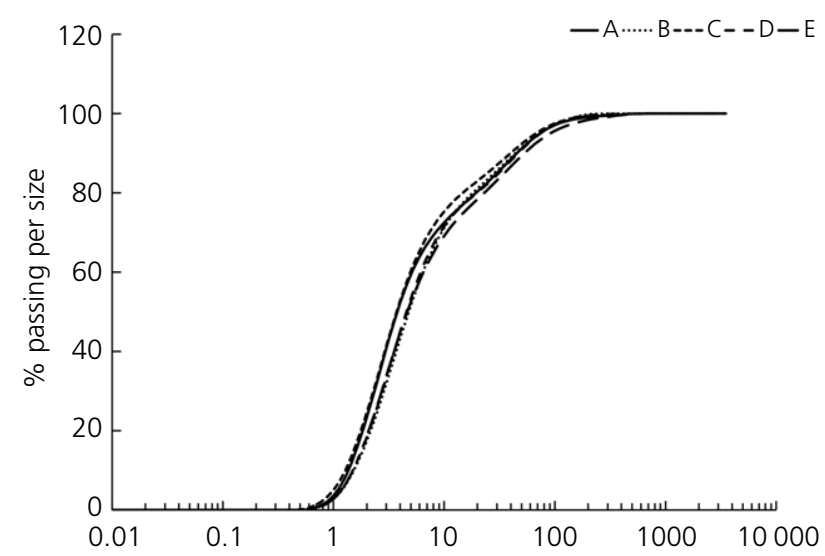

(a)

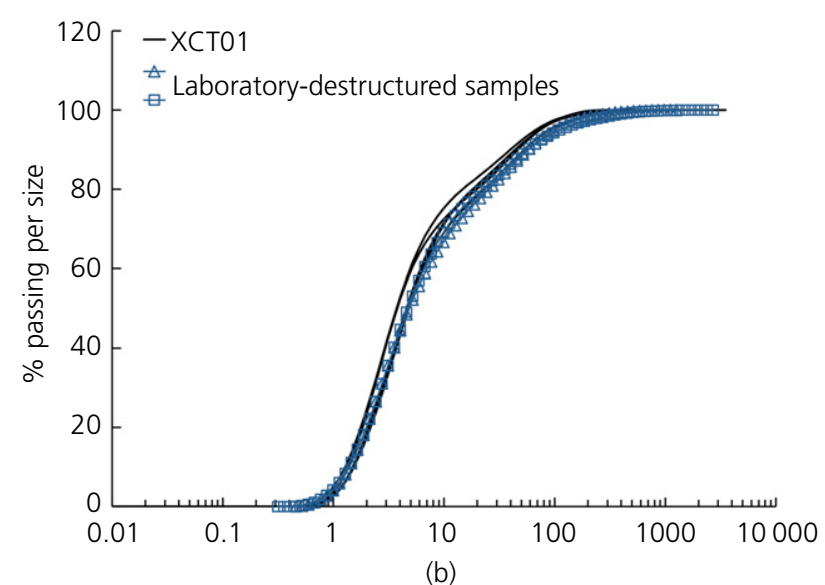

Figure 10. (a) PSA results for XCT01; (b) PSD comparison with data from Alvarez-Borges et al. (2020)

contact surface (Figure 11). However, whether these values reflect true physical conditions is difficult to corroborate with absolute certainty. An important consequence of the polychromatic nature of the cone beam used in laboratory-based XCT imaging is that the assumption of a linear correlation between X-ray attenuation and bulk density may not be fully accurate. This may be assessed for XCT01-02 and XCT02-03 by pairing the voxel values and densities of water $\left(\approx 1 \mathrm{Mg} / \mathrm{m}^{3}\right)$, thermoplastic piles (Table 1), intact chalk (Table 1) and crystallised calcite from macrofossils $\left(\approx 2.7 \mathrm{Mg} / \mathrm{m}^{3}\right.$; Clayton, 1983), as presented in Figure 12. A fairly linear trend may be observed in both cases. Thus, XCT-derived void ratios have been assumed to reflect physical conditions to acceptable accuracy.

\subsection{Limitations of the physical model}

Studies involving scaled physical models of pile installation in dense sands at normal gravity have shown that boundary effects can affect stress and strain measurements (Salgado 
International Journal of Physical Modelling in Geotechnics Volume 22 Issue 1
Investigation of pile penetration in

calcareous soft rock using X-ray

computed tomography

Alvarez-Borges, Ahmed, Madhusudhan and

Richards

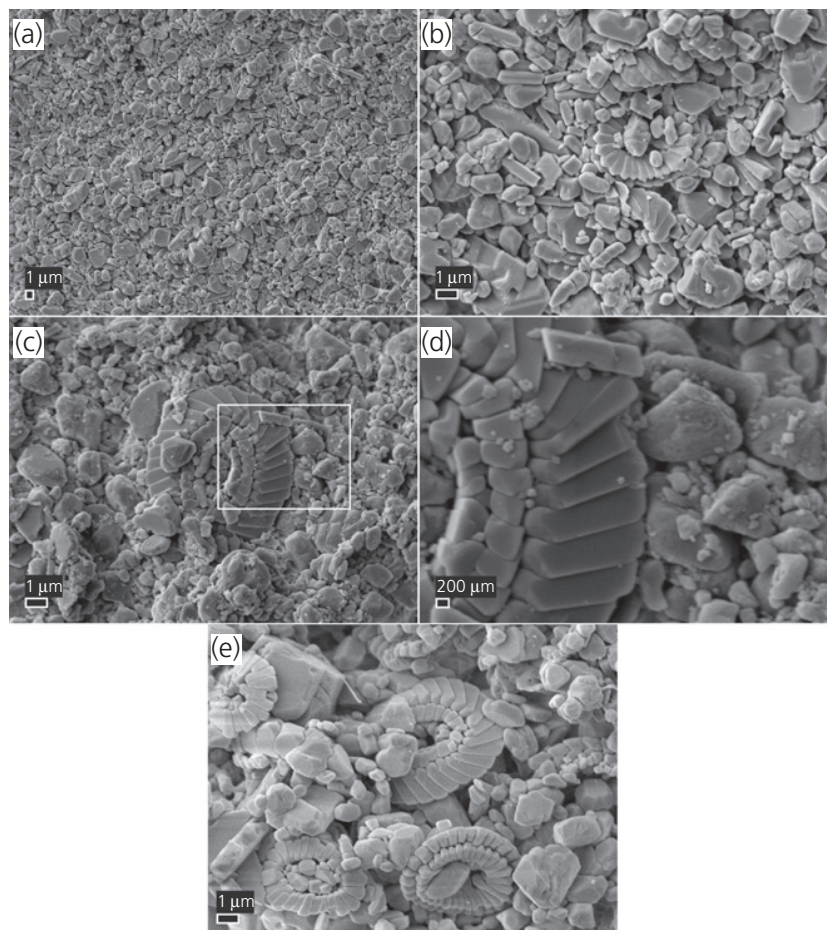

Figure 11. SEM images of annulus surface in contact with the pile shaft (XCT01): at $4.2 \mathrm{~mm}$ depth: (a) $7500 \times$ and (b) $20000 \times$ : at $21.2 \mathrm{~mm}$ depth, (c) $20000 \times$ and (d) close-up to rectangle area in (c); $60000 \times$. Intact chalk shown in (e) for reference

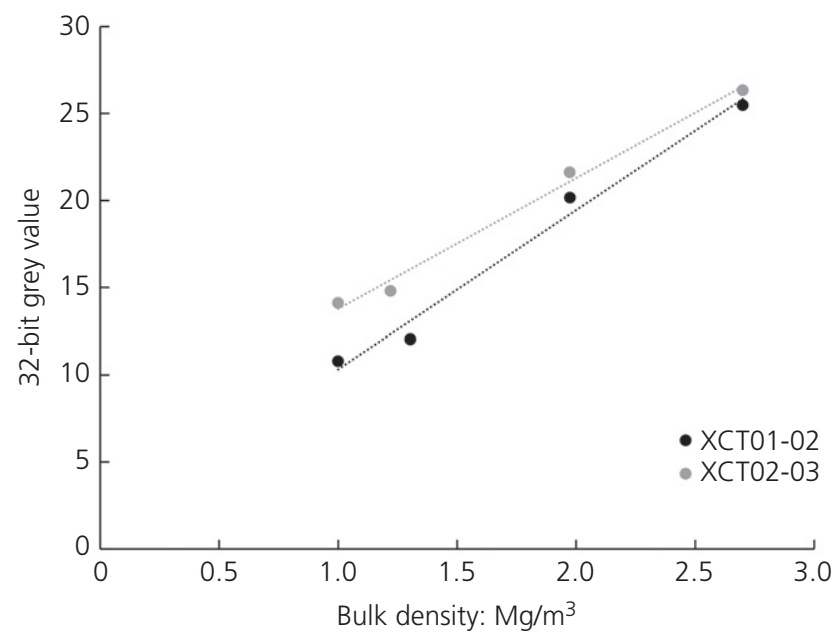

Figure 12. Calibration lines using GV counts of voxels containing water (pores), Perspex $\AA$ or PEEK (pile), intact chalk (average value across specimen height) and calcite (crystallised fossils)

et al., 1998). To mitigate this, specimen-to-pile diameter ratios of about 50 are often sought (Schnaid and Houlsby, 1991). However, such dimensions are not currently feasible in the vast majority of XCT imaging environments. This is in part due to a reduction in X-ray transmission and image resolution with increasing specimen size, for most XCT set-ups (Cnudde and Boone, 2013; Günther et al., 2019). Thus, the chosen specimen diameter was a compromise between the need to achieve the largest possible specimen-to-pile ratio and the need to keep the specimen size small enough to acquire full-field XCT images at voxel resolutions of about $100 \mu \mathrm{m}$. It is recognised that such compromise may have resulted in important boundary effects.

\subsection{Pile penetration processes and annulus characteristics}

Figures 7(a) and 9 evidence that the flat-tipped pile used in XCT01 compressed the chalk producing a bulb of dense crushed material ahead of the tip and the annulus feature behind it. The crushed and densified chalk bulb under the pile is analogous to the 'nose-cone' feature described by White and Bolton (2004) pertaining to model piles installed in sand. Chalk crushing and densification was accompanied by fracturing of the entire specimen. The longest fracture was approximately aligned with the pile axis, forming a sub-vertical discontinuity along the height of the chalk cylinder. This promoted lateral movement of intact chalk blocks, reflected by the large circumferential strains in Figure 6(b) (compared with XCT02). Additional cracks were created at an approximately perpendicular direction from the pile shaft and might have been prompted by the slightly inclined penetration of the pile.

The tubular pile of XCT02 crushed the chalk under the flat rim and cored into the specimen (Figures 7(b) and 9), which may have prevented specimen-wide fracturing. However, chalk became fragmented as it entered the tube pile, creating a plug composed of a mixture of crushed chalk and elongated cemented chalk fragments. The plug was observed to rise above the top surface of the specimen, as reported in field-scale pile testing (Ciavaglia et al., 2017). It is surmised that the halftoroid-shaped region of densified chalk ('nose-toroid') beneath the pile rim radially compressed the cemented chalk enclosed by this feature, eventually leading to tensile failure in the vertical direction, as schematically shown in Figure 13. Unequal displacement of some of the chalk fragments caused them to tilt as they entered the pile, eventually experiencing flexural loading and breaking up. Both tensile and flexural fracturing led to stress relaxation, facilitating the displacement of plug material as penetration progressed. These fracture-induced stress reductions are reflected by the serrated pile head loaddisplacement and circumferential strain profiles recorded during the installation of this pile (Figure 6). The displacement of destructured chalk and intact fragments through the tube pile resulted in the restriction of all visible structural changes in the chalk to the outer boundaries of the annulus (Figure 7(b)), 
International Journal of Physical Modelling in Geotechnics Volume 22 Issue 1
Investigation of pile penetration in

calcareous soft rock using X-ray

computed tomography

Alvarez-Borges, Ahmed, Madhusudhan and

Richards

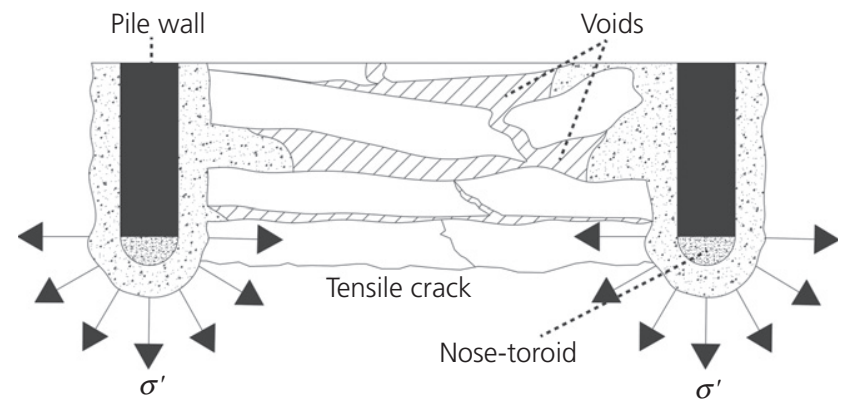

Figure 13. Schematic vertical cross-section view of the radial compression of chalk entering the tube pile

which was thinner than that of XCT01 and did not substantially change in thickness with penetration depth (Figure 14).

The PSD of the exhumed annulus material of XCT01 shown in Figure 10 exhibits notable similarities with that of the thoroughly remoulded chalk fines investigated by AlvarezBorges et al. (2020). This suggests that the material close to the pile shaft became completely destructured. The densely packed particle arrangements revealed by the SEM images shown in Figures 11(a)-11(d) support this.

These arrangements contrast with the open fabric and rich presence of intact coccoliths observed in the micrograph of intact chalk (Figure 11(e)).

\subsection{Cavity expansion theory}

Drained cylindrical cavity expansion theory is often used to interpret stress conditions around the tips of piles and

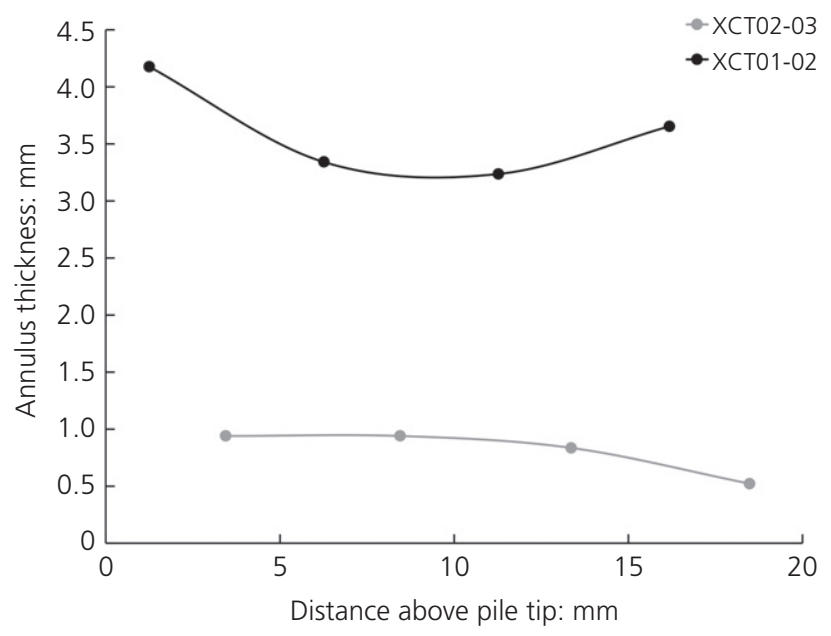

Figure 14. Comparison of annulus thickness with distance from the pile tip for both experiments penetrometers during penetration in sand (e.g. Jardine et al., 2013; Schneider, 2007; White et al., 2005). The approach is attractive due to its straightforward applicability and the availability of most of the material parameters required. Thus, a preliminary analysis based on drained cylindrical cavity expansion theory is carried out later in this paper to draw comparisons with the recent pile tests performed at the St Nicholas-at-Wade sampling site.

The basic analytical solution for drained cylindrical cavity expansion, as presented by $\mathrm{Yu}$ (2000) and Salgado and Randolph (2001), proposes that the penetration of piles into sand can be modelled as the growth of a cylindrical cavity in this medium. Thus, expansion finalises when the cavity radius, $r_{0}$, equals the pile radius. Sand is assumed to be at failure at the cavity wall when expansion ends, but plastic strain levels decrease as the distance from the cavity centreline, $r$, increases from $r_{0}$ until a radius $R$, after which no plastic strains are present. The 'limit pressure' at the cavity wall, $\sigma_{r 0}^{\prime}$, equivalent to the maximum radial effective stress acting perpendicularly to the pile shaft at the pile tip during penetration, is expressed as

3. $\sigma_{r_{0}}^{\prime}=\sigma_{\mathrm{R}}^{\prime}\left(\frac{R}{r_{0}}\right)^{(N-1) / N}$

with

4. $\quad N=\frac{1+\sin \phi^{\prime}}{1-\sin \phi^{\prime}}$

where $\phi^{\prime}$ is the operational angle of friction of the host medium and $\sigma_{\mathrm{R}}^{\prime}$ is the radial effective stress at the boundary between elastic and plastic deformations in the sand. $\sigma_{\mathrm{R}}^{\prime}$ is calculated as

5. $\sigma_{\mathrm{R}}^{\prime}=\frac{2 \sigma_{\mathrm{vi}}^{\prime} N\left(1+2 K_{0}\right)}{3(1+N)}$

where $\sigma_{\mathrm{vi}}^{\prime}$ is the pre-installation (or far-field) in situ vertical effective stress derived using the effective unit weight $\left(\gamma^{\prime}\right)$ of the host medium and the depth of analysis, $K_{0}$ is the horizontal to vertical effective stress ratio of the medium in onedimensional (1D) vertical compression and $N$ is calculated using the peak angle of friction, $\phi_{\mathrm{p}}^{\prime}$.

$\sigma_{r 0}^{\prime}$ is then determined by solving Equation 3 using a variety of soil models that aim to incorporate the non-linear stiffness and dilatancy behaviours of the host material (e.g. Jiang and Sun, 2012; Russell and Khalili, 2002; Salgado and Prezzi, 2007). When these parameters are not available, as for the present 
International Journal of Physical Modelling in Geotechnics Volume 22 Issue 1
Investigation of pile penetration in

calcareous soft rock using X-ray

computed tomography

Alvarez-Borges, Ahmed, Madhusudhan and

Richards experiments, a simplified solution can be applied. Salgado et al. (1997) propose that

6. $\sigma_{z}^{\prime}=2 \sigma_{r_{0}}^{\prime} \exp \left(\pi \tan \phi^{\prime}\right)\left[\frac{(1+C)^{1+\beta}-(1+\beta) C-1}{C^{2} \beta(1+\beta)}\right]$

where

7. $\beta=1-\frac{N-1}{N}$

and

8. $C=\exp [(\pi / 2) \tan \psi] \cot \left[45-\left(\phi_{\mathrm{c}}^{\prime} / 2\right)\right]$

where $\psi$ and $\phi_{\mathrm{c}}^{\prime}$ are the dilation and critical state angles, respectively, and $\sigma_{\mathrm{z}}^{\prime}$ is the effective vertical pile tip stress. As the material at the pile tip is assumed to be at the critical state during penetration, it may be proposed that $\psi=0$ and $\phi^{\prime}=\phi_{\mathrm{c}}^{\prime}$.

This simplified approach entails important drawbacks. For instance, it disregards the potential variability of critical state parameters with particle crushing (e.g. Altuhafi et al., 2018; Bandini and Coop, 2011), the dependency of $\phi^{\prime}$ and $\phi_{\mathrm{p}}^{\prime}$ on the state of the host material (e.g. Been and Jefferies, 1985; Bolton, 1986) and the stress/strain dependency of soil stiffness (e.g. Clayton and Heymann, 2001; Jovičić and Coop, 1997). As a result, calculations based on this approach can lead to significant inaccuracies in the estimation of $\sigma_{r 0}^{\prime}$. For piles installed in sand, some of these limitations can potentially be overcome using alternative methods such as 3D finite- and discrete-element modelling (e.g. Ciantia et al., 2019; Zhang et al., 2014). However, these methods are not directly applicable to piles installed in low-medium density chalk, as stiffness, peak strength and shearing behaviour are significantly affected by cementation and post-yield void ratio reductions.

\subsection{Comparison with field-scale pile tests}

Buckley et al. (2018a) recently carried out pile tests at the St Nicholas-at-Wade sampling site. Their work involved highly instrumented slowly jacked piles from which comparisons with this study may be drawn. Of special interest are the stresses developed at the pile tip, which have been associated by Buckley (2018) and Jardine et al. (2018) with the postinstallation vertical capacity of the pile.

Pile tip stresses for the model tests may be assumed to be about $80 \%$ of those calculated at the pile head during penetration, according to Hodges and Pink (1972) and Buckley et al. (2018a). This leads to maxima of $\sim 65 \mathrm{MPa}$ for the model piles of this study, which are notably higher than the $\approx 33 \mathrm{MPa}$ peak tip stresses reported by Buckley et al. (2018a) for their closed-ended $\approx 100 \mathrm{~mm}$ diameter piles. This disparity may be associated with the differences between the intact chalk samples used in the model tests and the chalk in the field. The piles tested by Buckley and colleagues were jacked directly into the Chalk mass, which exhibits natural discontinuities, while the model piles were jacked into specimens without pre-existing visible discontinuities. Chalk masses with closely spaced and open discontinuities, indicative of lower chalk grades, are associated with a lower lateral stiffness than formations with widely spaced and tightly closed discontinuities, representative of higher chalk grades (Lord et al., 2002; Matthews, 1993). Lateral stiffness, in turn, affects the confinement conditions of piles during installation, and impacts penetration resistance (Lehane and White, 2005; Wang et al., 2017).

The difference in confinement conditions during penetration between the scaled models and field experiments may be examined by comparing the theoretical elastic radial stiffness of the chalk in the field tests at the elastic-plastic boundary $R\left(E_{r=R}\right)$ with that of the Perspex ${ }^{\circledR}$ and epoxy confinement $\left(E_{r=a}\right)$ of the model tests, minding the model and cavity expansion theory limitations exposed before. To this end, radial strain at $R$ for field conditions, $\varepsilon_{r=R}$, may be calculated from elastic cylindrical cavity expansion theory for infinite media as (Yu, 2000)

9. $\varepsilon_{r=R}=\frac{\left(1-v_{\mathrm{c}}^{2}\right)}{E_{\mathrm{c}}}\left(\frac{\sigma_{\mathrm{R}}^{\prime}-2 K_{0} \sigma_{\mathrm{vi}}^{\prime} v_{\mathrm{c}}}{1-v_{\mathrm{c}}}\right)$

where $v_{\mathrm{c}}$ and $E_{\mathrm{c}}$ are Poisson's ratio and Young's modulus of the Chalk mass, respectively. Similarly, the radial strain on the inside wall of the model confinement (at the chalk-epoxy boundary), $\varepsilon_{r=a}$, can be calculated for finite media by considering that the radial stress acting on the outside of the Perspex ${ }^{\circledR}$ cylinder was zero (Yu, 2000):

10. $\varepsilon_{r=a}=\frac{\varepsilon_{\theta=b}}{2 a^{2}}\left(\frac{a^{2}\left(1-2 v_{\mathrm{p}}\right)-b^{2}}{1-v_{\mathrm{p}}}\right)$

while the radial stress on the inside wall of the model confinement, $\sigma_{r=a}^{\prime}$, can be defined as

11. $\sigma_{r=a}^{\prime}=\frac{\varepsilon_{\theta=b} E_{\mathrm{p}}}{2 a^{2}}\left(\frac{a^{2}-b^{2}}{1-v_{\mathrm{p}}^{2}}\right)$

where $\varepsilon_{\theta=b}$ is the circumferential strain measured on the outside of the Perspex ${ }^{\circledR}$ confinement (Figure $6(\mathrm{~b})$ ), $v_{\mathrm{p}}$ and $E_{\mathrm{p}}$ are Poisson's ratio and Young's modulus of the confinement, respectively, and $a$ and $b$ are the inside and outside radii of the confinement, equal to 50 and $62.5 \mathrm{~mm}$ in each case (Table 2). 
$E_{r=R}$ may then be calculated as $\delta \sigma_{\mathrm{R}}^{\prime} / \delta \varepsilon_{r=R}$ by considering in Equations 5 and 9 that $E_{\mathrm{c}}=2 G_{\mathrm{c}}\left(1+v_{\mathrm{c}}\right)$, where $G_{\mathrm{c}}$ is the Chalk mass shear modulus. Then, it may be taken from Buckley (2018) that $G_{\mathrm{c}}=800 \mathrm{MPa}, K_{0}=0.4$ and $\phi_{\mathrm{p}}^{\prime}=36.5^{\circ}$, from Matthews (1993) that $v_{\mathrm{c}}=0.25$, and from Table 1 that $\gamma^{\prime}=$ $1.55 \mathrm{Mg} / \mathrm{m}^{3}$. Thus, $E_{r=R} \sim 2.02 \mathrm{GPa}$. For $E_{r=a}=\delta \sigma_{r=a}^{\prime} / \delta \varepsilon_{r=a}$, it may be assumed in Equation 11 that the epoxy and the Perspex ${ }^{\circledR}$ share the same Young's modulus and Poisson's ratio, so that $E_{\mathrm{p}}=3.16 \mathrm{GPa}$ and $v_{\mathrm{p}}=0.33$ (after Lu et al., 1997). Thus, $E_{r=a} \sim 0.88 \mathrm{GPa}$. These stiffness estimates suggest $\sigma_{r=a}^{\prime}$ values between $\sim 120$ and $400 \mathrm{kPa}$ for the model tests at the end of installation, and $\sigma_{\mathrm{R}}^{\prime}$ values of $\sim 35 \mathrm{kPa}$ for the field tests. It should be noted that the final pile tip depth for both XCT experiments lies above the strain-gauged horizon. Estimated radial stresses may have increased further if the tip had reached this horizon, as suggested by the progressive increase in circumferential strain with pile penetration shown in Figure 6(b).

The above cylindrical expansion calculations suggest that the physical models underestimated the far-field in situ radial stiffness. This lower stiffness could be associated with the formation and opening of cracks in XCT01 (Figure 7). Significantly, it was expected that a lower far-field confinement stiffness would lead to lower pile penetration resistances, but the opposite was observed in the model tests. Thus, the higher penetration resistances measured in the model experiments indicate that the effect of the confinement stiffness may have been partially offset by other factors. For instance, lower chalk grades are associated with decreasing CPT resistances (Anusic, 2018; Brown et al., 2018), which may be in turn linked to the increased compressibility of such grades (Matthews, 1993).

A further factor leading to high penetration resistances in the model tests may be the slow penetration rates used, which were aimed at achieving fully drained penetration. The resulting crushed chalk is thus notably denser than the surrounding intact material. In contrast, full-scale piles in chalk are usually impactdriven, which entails fast penetration rates and near-undrained conditions at the pile tip. This is thought to lead to limited densification, high pore-pressure developments, very loose ('puttified') crushed chalk annuli, and low penetration resistances (Anusic, 2018; Jardine et al., 2018). Open-ended test piles driven at the St Nicholas-at-Wade site by Buckley et al. (2018b) at average penetration velocities between 342 and $1374 \mathrm{~mm} / \mathrm{min}$ mobilised penetration resistances of about $15.8 \mathrm{MPa}$. These are broadly comparable to the $36 \mathrm{~mm}$ diameter CPT cone resistances of 10-20 MPa reported by the same authors, which were carried out at the standard $1200 \mathrm{~mm} / \mathrm{min}$. The slowly jacked (204-288 mm/min) closed-ended piles tested by Buckley et al. (2018a) mobilised higher resistances, between 12 and $33 \mathrm{MPa}$, as mentioned earlier. In comparison, the model piles of this study were installed at $0.174 \mathrm{~mm} / \mathrm{min}$ and mobilised pile tip stresses of up to $\sim 65 \mathrm{MPa}$.

\subsection{Effective stress-void ratio state at the model pile tip}

The effective stress and void ratio changes that occur during pile penetration in chalk have recently been characterised using critical state soil mechanics (Alvarez-Borges, 2019; Buckley, 2018; Geduhn et al., 2018; Lord et al., 1994). This approach assumes that the effective stress-void ratio state of a chalk element in the path of a penetrating pile will tend towards the critical state line (CSL) as the pile tip approaches and the chalk becomes crushed and remoulded. Thus, the unit shaft friction mobilised at the pile tip may be considered a function of the void ratio of the chalk as it reaches the pile surface.

Whether the annulus material in the present experiments attained the critical state as it reached the pile tip shoulder as assumed by cavity expansion theory and by the effective stress framework for pile penetration may be very preliminarily assessed using the measured installation force and the XCT-derived void ratios. However, matching these two parameters is not straightforward, because the measured pile head displacements include the elastic compression of the pile, pile deflection and localised pile head damage in the case of XCT02. A rudimentary approach may be drawn by assuming for stage 2 and subsequently that penetration occurred solely after the end of the 'reloading' portion of the load-displacement curves of Figure 6(a), that is, during the 'post-yield' linear increase in pile head load marked by dotted lines. Thus, a similarly linear increase in pile tip resistance with penetration depth may be assumed for each installation step.

Cylindrical cavity expansion theory may be then invoked to estimate $\sigma_{r 0}^{\prime}$ acting at the pile tip during penetration, using the simplified solution presented before (Equations 6-8) and considering that $\phi_{\mathrm{c}}^{\prime}=33.7^{\circ}$ according to Alvarez-Borges et al. (2020). Very approximate $\sigma_{r 0}^{\prime}$ values for the pile tip region may be thereafter computed and paired with the XCT-derived annulus void ratios, as shown in Figure 15. This figure suggests that the annulus material did not reach the CSL (derived from Alvarez-Borges et al., 2020) in the looser, shallower regions of the feature, but tended to do so at higher stresses and lower void ratios.

The non-convergence with the CSL at lower stresses and higher void ratios may be attributed to penetration processes that are not compatible with the simplified drained cavity expansion solution and the effective stress framework for pile penetration. For instance, the formation and opening of fractures in XCT01 suggests that pile insertion was partially allowed by the lateral displacement of cemented chalk blocks rather than purely by the crushing and densification of the chalk under the advancing pile tip. Likewise, the formation of the plug in XCT02 involved the fracturing and displacement of cemented chalk shards, which were removed from the tip 
International Journal of Physical Modelling in Geotechnics Volume 22 Issue 1
Investigation of pile penetration in

calcareous soft rock using X-ray

computed tomography

Alvarez-Borges, Ahmed, Madhusudhan and

Richards

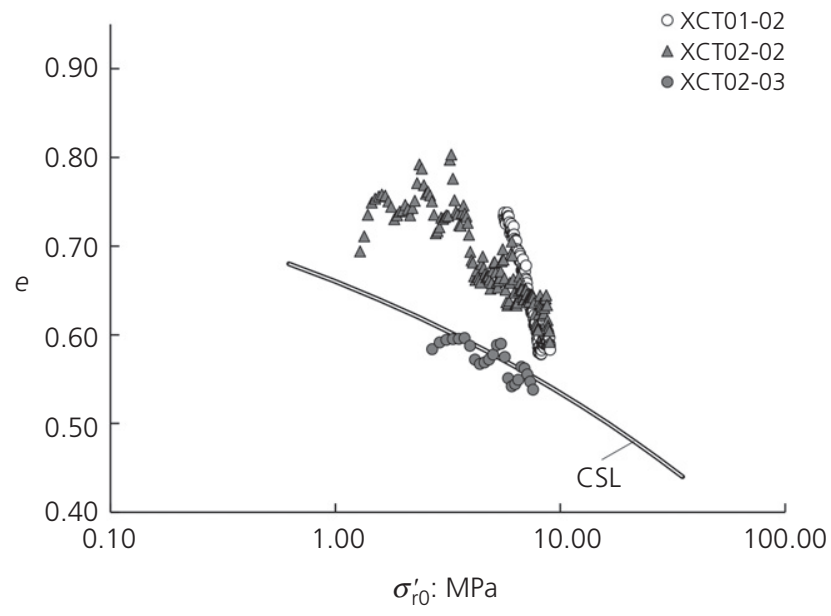

Figure 15. Estimated $\sigma_{r 0}^{\prime}$ at pile tip depth from cylindrical cavity expansion method plotted against XCT-derived void ratios

region and displaced through the pile opening instead of becoming crushed and densified under the rim. The aforementioned boundary effects and the use of a simplified linear elastic-plastic soil model that omits the role of cementation and hardening in the cavity expansion solution may have also played a role in the results obtained. It could be speculated, however, that tip penetration processes incompatible with the assumptions of the simplified cavity expansion solution, like the creation and opening of discontinuities, may have reduced significantly for XCT02 as penetration depth and stresses increased, favouring chalk crushing and densification instead. This, in turn, might have led to convergence towards the CSL.

\section{Conclusions}

An investigation into the processes involved in the slow, drained, penetration of cylindrical open- and closed-ended piles into intact chalk, a soft calcareous rock, has been carried out using microfocus XCT. The aim was to quantify variations in density associated with penetration-induced destructuration and to correlate these variations with the applied loads. Significant outcomes were as follows.

- Regardless of the tip condition, model pile jacking crushed the chalk in the path of the pile and created a crushed chalk sleeve or 'annulus' of higher density than the cemented chalk enclosing it. Post-test exhumation followed by laser-diffraction PSAs and SEM imaging of the annulus material suggested that it was thoroughly uncemented and that it was comparable with remoulded chalk produced in the laboratory.

- A region of heavily compressed material formed ahead of the pile tip, producing a 'nose-cone' and 'nose-toroid' feature under the closed- and open-ended piles, respectively. Similar features have been reported previously in model tests in sands.

- The penetration of the closed-ended pile was aided by the development and aperture of fractures across the chalk specimen. This behaviour was associated with a relatively low confinement stiffness and may not occur in field scenarios.

- The open-ended pile cored into the specimen. This prevented specimen-wide fracturing, but the chalk plug shattered as it entered the pile. Plug fracturing produced stress increase and relaxation cycles during penetration.

- The inferred pile tip stresses during penetration were found to be substantially higher than those measured in field-scale instrumented pile tests. This was attributed to the slower penetration velocities used in the model experiments and to the reduced compressibility of intact chalk compared with that of the rock mass in the field, which may contain numerous discontinuities.

- The pairing of estimated pile tip stresses and XCT-derived annulus void ratios using simplified cylindrical cavity expansion equations suggested a convergent tendency towards the CSL of reconstituted chalk during pile installation, as assumed by the effective stress model for pile penetration in chalk recently proposed in the literature. However, this analysis was deemed to be limited by the unfitness of the simplified cavity expansion soil model to fully incorporate the mechanical behaviour of low-medium density chalk, the formation of discontinuities during penetration, and the boundary conditions of the physical models.

\section{Acknowledgements}

This research has been sponsored by the National Council of Science and Technology of Mexico (Consejo Nacional de Ciencia y Tecnología, CONACyT) and by the Faculty of Engineering and Physical Sciences of the University of Southampton. The authors are grateful for the support of Dr Mark Mavrogordato, Dr Orestis Katsamenis and Dr Kathryn Rankin from the $\mu$-Vis X-ray Imaging Centre of the University of Southampton.

\section{REFERENCES}

Aldiss DT, Bloomfield JR, Buckley DK et al. (2004) A Geological Model for the Chalk of East Kent. Volume 1 of 2: Report. British Geological Survey, London, UK.

Altuhafi FN, Jardine RJ, Georgiannou VN and Moinet WW (2018) Effects of particle breakage and stress reversal on the behaviour of sand around displacement piles. Géotechnique 68(6): 546-555, https://doi.org/10.1680/jgeot.17.P.117.

Alvarez-Borges FJ (2019) The Shaft Capacity of Small Displacement Piles in Chalk. PhD thesis, University of Southampton, Southampton, UK.

Alvarez-Borges FJ, Madhusudhan BN and Richards DJ (2020) Mechanical behaviour of low-medium density destructured White Chalk. 
International Journal of Physical Modelling in Geotechnics Volume 22 Issue 1
Investigation of pile penetration in calcareous soft rock using X-ray computed tomography

Alvarez-Borges, Ahmed, Madhusudhan and Richards
Geotechnique Letters 10(2): 360-366, https://doi.org/10.1680/ jgele.20.00009.

Anusic I (2018) Installation of Monopiles for Offshore Wind Turbine Foundations. PhD thesis, Norwegian University of Science and Technology, Trondheim, Norway.

Bandini V and Coop MR (2011) The influence of particle breakage on the location of the critical state line of sands. Soils and Foundations 51(4): 591-600, https://doi.org/10.3208/sandf.51.591.

Been K and Jefferies MG (1985) A state parameter for sands. Géotechnique 35(2): 99-112, https://doi.org/10.1680/geot.1985. 35.2.99.

Bolton MD (1986) The strength and dilatancy of sands. Géotechnique 36(1): 65-78, https://doi.org/10.1680/geot.1986.36.1.65.

Bristow R, Mortimore R and Wood C (1997) Lithostratigraphy for mapping the chalk of southern England. Proceedings of the Geologist Association 108(4): 293-315, https://doi.org/10.1016/ S0016-7878(97)80014-4.

Brown M, Taylor L and Sadek T (2018) Determination of chalk structure using cone penetration tests. In Engineering in Chalk, Proceedings of the Chalk 2018 Conference (Lawrence J, Preene M, Lawrence U and Buckley RM (eds)). ICE Publishing, London, UK, pp. 509-514, https://doi.org/10.1680/eiccf.64072.509.

BSI (2009) BS ISO 13320:2009. Particle size analysis - Laser diffraction methods. British Standards Institution, London, UK.

Buckley RM (2018) The Axial Behaviour of Displacement Piles in Chalk. $\mathrm{PhD}$ thesis, Imperial College London, London, UK.

Buckley RM, Jardine RJ, Kontoe S and Lehane BM (2018a) Effective stress regime around a jacked steel pile during installation, ageing and load testing in chalk. Canadian Geotechnical Journal 55(11): 1577-1591, https://doi.org/10.1139/cgj-2017-0145.

Buckley RM, Jardine RJ, Kontoe S, Parker D and Schroeder FC (2018b) Ageing and cyclic behaviour of axially loaded piles driven in chalk. Géotechnique 68(2): 146-161, https://doi.org/10.1680/jgeot.17.P.012.

Buckley RM, McAdam RA, Byrne BW et al. (2020) Optimization of impact pile driving using optical fiber Bragg-grating measurements. Journal of Geotechnical and Geoenvironment Engineering 146(9): 04020082, https://doi.org/10.1061/(ASCE)GT.1943-5606.0002293.

Canny J (1986) A computational approach to edge detection. IEEE Trans. Pattern Analysis and Machine Intelligence 8(6): 679-698, https://doi.org/10.1109/TPAMI.1986.4767851.

Chan DLH, Buckley RM, Liu T and Jardine RJ (2019) Laboratory investigation of interface shearing in chalk. In 7th International Symposium on Deformation Characteristics of Geomaterials (Tarantino A and Ibraim E (eds)). EDP Sciences, Les Ulis, France, article no. 13009, https://doi.org/10.1051/e3sconf/20199213009.

Ciantia MO, O'Sullivan C, Arroyo M and Gens A (2019) Breakage and critical state via DEM. In Proceedings of the XVII European Conference on Soil Mechanics and Geotechnical Engineering (Sigursteinsson H, Erlingsson S and Bessason B (eds)). Icelandic Geotechnical Society, Reykjavik, Iceland, pp. 958-965, https://doi.org/10.32075/17ECSMGE-2019-0958.

Ciavaglia F, Carey J and Diambra A (2017) Time-dependent uplift capacity of driven piles in low to medium density chalk. Geotechnique Letters 7(1): 90-96, https://doi.org/10.1680/jgele.16.00162.

Clayton CRI (1983) The influence of diagenesis on some index properties of chalk in England. Géotechnique 33(3): 225-241, https://doi.org/10.1680/geot.1983.33.3.225.

Clayton CRI and Heymann G (2001) Stiffness of geomaterials at very small strains. Géotechnique 51(3): 245-255, https://doi.org/10.1680/ geot.51.3.245.39363.

Clayton CRI and Serratrice JF (1997) General report session 2: the mechanical properties and behaviour of hard soils and soft rocks. In Proceedings of an International Symposium on Geotechnical
Engineering of Hard Soils - Soft Rocks (Anagnostopoulos A, Schlosser F, Kalteziotis N and Frank R (eds)). Balkema, Rotterdam, the Netherlands, vol. 3, pp. 1839-1877.

Clayton CRI, Matthews MC and Heymann G (2003) The chalk. In Characterisation and Engineering Properties of Natural Soils (Tan TS, Phoon KK, Hight DW and Leroueil S (eds)). Balkema, Lisse, the Netherlands, vol. 2, pp. 1402-1434.

Cnudde V and Boone MN (2013) High-resolution X-ray computed tomography in geosciences: a review of the current technology and applications. Earth-Science Reviews 123: 1-17, https://doi.org/ 10.1016/j.earscirev.2013.04.003.

Cuccovillo T and Coop MR (1999) On the mechanics of structured sands. Géotechnique 49(6): 741-760, https://doi.org/10.1680/geot.1999. 49.6.741.

Desrues J (2004) Tracking strain localisation in geomaterials using computerized tomography. In X-ray CT for Geomaterials: Soils, Concrete, Rocks, Proceedings of the International Workshop on $X$-ray CT for Geomaterials (Otani J and Obara Y (eds)). Balkema, Lisse, the Netherlands, pp. 15-42.

Geduhn M, Barbosa P, Dührkop J et al. (2018) Offshore pile load tests in chalk to support the design of jacket foundations. Proceedings of the Institution of Civil Engineers - Geotechnical Engineering 171(6): 508-517, https://doi.org/10.1680/jgeen.17.00217.

Günther B, Hehn L, Jud C et al. (2019) Full-field structured-illumination super-resolution X-ray transmission microscopy. Nature Communications 10: article no. 2494, https://doi.org/10. 1038/s41467-019-10537-x

Hancock JM (1975) The petrology of chalk. Proceedings of the Geologist Association 86(4): 499-535, https://doi.org/10.1016/ S0016-7878(75)80061-7.

Hobbs NB and Atkinson MS (1993) Compression and tension tests on an open ended tube pile in chalk. Ground Engineering 26(3): 30-34.

Hodges WG and Pink S (1972) The use of penetrometer soundings in the estimation of pile bearing capacity and settlement for driven piles in highly weathered chalk in Portsmouth areas as an alternative to site investigations by borehole sampling and laboratory testing. In Stress-Strain Behaviour of Soils: Proceedings of the Roscoe Memorial Symposium (Parry RHG (ed.)). Foulis, Henley-on-Thames, UK, pp. 707-723.

Hsieh J (2015) Computed Tomography: Principles, Design, Artifacts, and Recent Advances, 3rd edn. Society of Photo-Optical Instrumentation Engineers (SPIE), Bellingham, WA, USA.

Jardine RJ, Zhu BT, Foray P and Yang ZX (2013) Interpretation of stress measurements made around closed-ended displacement piles in sand. Géotechnique 63(8): 613-627, https://doi.org/10.1680/ geot.9.P.138.

Jardine RJ, Buckley RM, Kontoe S, Barbosa P and Schroeder FC (2018) Behaviour of piles in driven chalk. In Engineering in Chalk, Proceedings of the Chalk 2018 Conference (Lawrence J, Preene M, Lawrence U and Buckley RM (eds)). ICE Publishing, London, UK, pp. 33-51, https://doi.org/10.1680/eiccf.64072.033.

Jiang MJ and Sun YG (2012) Cavity expansion analyses of crushable granular materials with state-dependent dilatancy. International Journal for Numerical and Analytical Methods 36(6): 723-742, https://doi.org/10.1002/nag.1027.

Jovičić V and Coop MR (1997) Stiffness of coarse-grained soils at small strains. Géotechnique 47(3): 545-561, https://doi.org/10.1680/geot. 1997.47.3.545.

Kanji MA (2014) Critical issues in soft rocks. Journal of Rock Mechanics and Geotechnical Engineering 6(3): 186-195, https://doi.org/10.1016/j.jrmge.2014.04.002.

Ketcham RA and Carlson WD (2001) Acquisition, optimization and interpretation of X-ray computed tomographic 
International Journal of Physical Modelling in Geotechnics Volume 22 Issue 1
Investigation of pile penetration in

calcareous soft rock using X-ray

computed tomography

Alvarez-Borges, Ahmed, Madhusudhan and

Richards imagery: applications to the geosciences. Computers \& Geosciences - UK 27(4): 381-400, https://doi.org/10.1016/S00983004(00)00116-3.

Kishida $\mathrm{H}$ and Uesugi M (1987) Tests of the interface between sand and steel in the simple shear apparatus. Géotechnique 37(1): 45-52, https://doi.org/10.1680/geot.1987.37.1.45.

Lagioia R and Nova R (1995) An experimental and theoretical study of the behaviour of a calcarenite in triaxial compression. Géotechnique 45(4): 633-648, https://doi.org/10.1680/geot.1995.45. 4.633.

Lehane BM and White DJ (2005) Lateral stress changes and shaft friction for model displacement piles in sand. Canadian Geotechnical Journal 42(4): 1039-1052, https://doi.org/10.1139/ T05-023.

Leroueil S and Vaughan PR (1990) The general and congruent effects of structure in natural soils and weak rocks. Géotechnique 40(3): 467-488, https://doi.org/10.1680/geot.1990.40.3.467.

Lord JA, Twine DP and Yeow H (1994) CIRIA Project Report 11 . Foundations in Chalk. Construction Industry Research and Information Association (CIRIA), London, UK.

Lord JA, Clayton CRI and Mortimore RN (2002) CIRIA Report C 574. Engineering in Chalk. Construction Industry Research and Information Association (CIRIA), London, UK.

Lu H, Zhang X and Knauss WG (1997) Uniaxial, shear, and Poisson relaxation and their conversion to bulk relaxation: studies on poly (methyl methacrylate). Polymer Composites 18(2): 211-222, doi:/10.1002/pc.10275.

Madhusudhan BN and Baudet BA (2014) Influence of reconstitution method on the behaviour of completely decomposed granite. Géotechnique 64(7): 540-550, https://doi.org/10.1680/ geot.13.P.159.

Mail N, Moseley DJ, Siewerdsem JH and Jaffray DA (2009) The influence of bowtie filtration on cone-beam CT image quality. Medical Physics 36(1): 22-32, https://doi.org/10.1118/1.3017470.

Markins SR (2014) Artifacts interfering with interpretation of cone beam computed tomography images. Dental Clinics of North America 58(3): 485-495, https://doi.org/10.1016/j.cden.2014.04.007.

Matthews MC (1993) The Mass Compressibility of Fractured Chalk. PhD thesis, University of Surrey, Guildford, UK.

Mortimore RN (1986) Stratigraphy of the upper cretaceous white chalk of Sussex. Proceedings of the Geologists' Association 97(2): 97-139, https://doi.org/10.1016/s0016-7878(86)80065-7.

Mull RT (1984) Mass estimates by computed-tomography - physical density from CT numbers. American Journal of Roentgenology 143(5): 1101-1104, https://doi.org/10.2214/ajr.143.5.1101.

Otani J, Watanabe Y and Chevalier B (2010) Introduction of X-ray CT application in geotechnical engineering - theory and practice. In 9th World Congress on Computational Mechanics and 4th Asian Pacific Congress on Computational Mechanics (Khalili N, Valliappan S, Li Q and Russell AR (eds)). IOP Publishing, Bristol, UK, vol. 10, pp. 1-10, https://doi.org/10.1088/1757-899x/10/1/ 012089.

Phillips DH and Lannutti JJ (1997) Measuring physical density with $\mathrm{X}$-ray computed tomography. NDT\&E International 30(6): 339-350, https://doi.org/10.1016/S0963-8695(97)00020-0.

Russell AR and Khalili N (2002) Drained cavity expansion in sands exhibiting particle crushing. International Journal for Numerical and Analytical Methods 26(4): 323-340, https://doi.org/10.1002/ nag. 203.

Salgado R and Prezzi M (2007) Computation of cavity expansion pressure and penetration resistance in sands. International Journal of Geomechanics 7(4): 251-265, https://doi.org/10.1061/(ASCE) 1532-3641(2007)7:4(251)
Salgado R and Randolph MF (2001) Analysis of cavity expansion in sand. International Journal of Geomechanics 1(2): 175-192, https://doi.org/10.1061/(ASCE)1532-3641(2001)1:2(175).

Salgado R, Mitchell JK and Jamiolkowski M (1997) Cavity expansion and penetration resistance in sand. Journal of Geotechnical and Geoenvironmental Engineering 123(4): 344-354, https://doi.org/ 10.1061/(Asce)1090-0241(1997)123:4(344).

Salgado R, Mitchell JK and Jamiolkowski M (1998) Calibration chamber size effects on penetration resistance in sand. Journal of Geotechnical and Geoenvironmental Engineering 124(9): 878-888, https://doi.org/10.1061/(ASCE)1090-0241(1998)124:9(878).

Schnaid F and Houlsby GT (1991) An assessment of chamber size effects in the calibration of in situ tests in sand. Géotechnique 41(3): 437-445, https://doi.org/10.1680/geot.1991.41.3.437.

Schneider JA (2007) Analysis of Piezocone Data for Displacement Pile Design. PhD thesis, University of Western Australia, Crawley, WA, Australia.

Wang J, Liu S and Cheng YP (2017) Role of normal boundary condition in interface shear test for the determination of skin friction along pile shaft. Canadian Geotechnical Journal 54(9): 1245-1256, https://doi.org/10.1139/cgj-2016-0312.

White DJ and Bolton MD (2004) Displacement and strain paths during plane-strain model pile installation in sand. Géotechnique 54(6): 375-397, https://doi.org/10.1680/geot.2004.54.6.375.

White DJ, Schneider JA and Lehane BM (2005) The influence of the effective area ratio on shaft friction of displacement piles in sand. In Frontiers in Offshore Geotechnics (Gourvenec S and Cassidy M (eds)). Taylor \& Francis, London, UK, pp. 741-747.

Yu HS (2000) Cavity Expansion Methods in Geomechanics. Springer, Dordrecht, the Netherlands.

Zhai H, Canbulat I, Hebblewhite B and Zhang C (2017) Review of current empirical approaches for determination of the weak rock mass properties. Procedia Engineering 191: 908-917, https://doi.org/ 10.1016/j.proeng.2017.05.261.

Zhang G, Marshall N, Jacobs R, Liu Q and Bosmans H (2013) Bowtie filtration for dedicated cone beam CT of the head and neck: a simulation study. The British Journal of Radiology 86(1028) article no. 20130002, https://doi.org/10.1259/bjr.20130002.

Zhang C, Yang ZX, Nguyen GD, Jardine RJ and Einav I (2014) Theoretical breakage mechanics and experimental assessment of stresses surrounding piles penetrating into dense silica sand. Geotechnique Letters 4(1): 11-16, https://doi.org/10.1680/geolett.13.00075.

\section{How can you contribute?}

To discuss this paper, please email up to 500 words to the editor at journals@ice.org.uk. Your contribution will be forwarded to the author(s) for a reply and, if considered appropriate by the editorial board, it will be published as discussion in a future issue of the journal.

International Journal of Physical Modelling in Geotechnics relies entirely on contributions from the civil engineering profession (and allied disciplines). Information about how to submit your paper online is available at www. icevirtuallibrary.com/page/authors, where you will also find detailed author guidelines. 